\section{Beyond vectors and vessels: reflections on women and primary health care reform in Canada ${ }^{1}$}

\author{
Ann Pederson ${ }^{2}$ \\ and Lissa Donner ${ }^{3}$
}

Key words: primary health care, health care economics and organizations, health services accessibility, delivery of health care, Canada.

\footnotetext{
1 An earlier version of this paper was prepared for the National Workshop on Women and Primary Health Care, which was held in February 2004 and was sponsored by Women and Health Care Reform (formerly the National Coordinating Group on Health Care Reform and Women), funded by Health Canada, and organized by Women and Health Care Reform and the Prairie Women's Health Centre of Excellence in Winnipeg, Manitoba.

2 British Columbia Centre of Excellence for Women's Health, Vancouver, British Columbia, Canada. Send correspondence and reprint requests to: Ann Pederson, Box 48, Room E311, 4500 Oak Street, Vancouver, BC, Canada V6H 3N1; telephone: 604-875-2633; fax: 604-8753716; email: apederson@cw.bc.ca.

3 Consultant, Winnipeg, Manitoba, Canada.
}

The future of primary health care (PHC) has been the topic of intense debate and discussion in Canada. In 2003, Canada's First Ministers (the Prime Minister and the Provincial and Territorial Premiers) adopted the Accord on Health Care Renewal (1). PHC was one of five priority-action areas named in the Accord. However, the Accord was adopted by a federal Liberal government that was subsequently replaced, in early 2006 , by a minority Conservative one. The new government did not identify PHC renewal as one of its top priorities, despite the existence of the Accord. The Primary Health Care Transition Fund (PHCTF), initiated in 2000 to support innovations in PHC practice, also completed its funding of projects in 2006. Evaluations of those projects and the overall initiative are underway. These developments raise questions about the future of PHC reform in Canada at the level of the federal government; however, they do not diminish the importance of PHC reform to the provincial and territorial governments, which are constitutionally responsible for the delivery of health services. Further, the issues that the Accord was intended to address-challenges to the PHC, stimulating innovations, and naming $\mathrm{PHC}$ as a cornerstone of the Canadian health care system-remain concerns of health care providers, patients, and managers alike. Moreover, the question of concern here- the lack of gender sensitivity in overall package of reforms-remains a problem despite the change in government.

The Accord on Health Care Renewal (1) states, in part: "The key to efficient, timely, quality care is primary health care reform. First Ministers agree that the core building blocks of an effective primary health care system are improved continuity and coordination of care, early detection and action, better information on needs and outcomes, and new and stronger incentives to ensure that new approaches to care are swiftly adopted and here to stay."

Given the prominence of PHC in the Accord, this paper examines the PHC vision and reforms underway in Canada, and specifically, the implications for women and women's health. It is our contention that the current approach to PHC reform has not given gender-related issues adequate importance. The particular model of PHC being promulgated, a lack of understanding of genderspecific PHC needs, and a limited view of women's roles in health and health care are at the crux of its shortcomings. 


\section{WHAT IS PRIMARY HEALTH CARE?}

In 1978, the World Health Organization (WHO) stated in the Declaration of Alma-Ata (2): "The people have the right and duty to participate individually and collectively in the planning and implementation of their health care . . . Primary health care is the key to attaining this target as part of development in the spirit of social justice. Primary health care is essential health care based on practical, scientifically sound, and socially acceptable methods and technology made universally accessible to individuals and families in the community through their full participation and at a cost that the community and country can afford to maintain at every stage of their development in the spirit of self-reliance and self-determination ... It is the first level of contact of individuals, the family and community with the national health system bringing health care as close as possible to where people live and work, and constitutes the first element of a continuing health care process." In short, according to the WHO statement, PHC encompasses disease prevention, health promotion, and curative and rehabilitation services.

The early women's health movement of the 1960s and 1970s was important in arguing for a broader view of health policy, one that looked beyond health as the absence of disease to a recognition of health as a resource for living. It was the women's movement, in part, that pioneered the political approaches to health and health care, taking them from the domain of the personal to the domain of the political. As Barbara Ehrenreich and Deirdre English wrote in Complaints and Disorders (3) five years before the Declaration of Alma-Ata: "This, to us, is the most profoundly liberating feminist insight-the understanding that our oppression is socially, and not biologically, ordained. To act on this understanding is to ask for more than 'control over our own bodies.' It is to ask for, and struggle for, control over the social options available to us, and control over all the institutions of society that now define those options."

Health Canada, the Federal Department of Health of Canada, has a longstanding commitment to understanding the determinants of health, including income, social status, employment, education, social environments, physical environments, healthy child development, personal health practices and coping skills, health services, social support networks, gender, and culture (4). This commitment dates back to the 1974 report by then-Federal Minister of Health Marc Lalonde, A New Perspective on the Health of Canadians (5). Health Canada also has an expressed commitment to both gender-based analysis and women's health, as evidenced by its Women's Health Strategy, its Gender-based Analysis Policy, and its guide to gender-based analysis, Exploring Concepts in Gender and Health $(4,6,7)$.

To date, however, the importance of nonmedical determinants of health has not been evident in Health Canada's work on PHC reform. Other key government-related initiatives have similarly held a narrow view of PHC. For example, in its 2003 report entitled Choices for Change: The Path for Restructuring Primary Healthcare Services in Canada, the Canadian Health Services Research Foundationthe primary funding agency for health services research-defined PHC without any reference to the broader determinants of health (8): "The term 'primary health care' has been interpreted in different ways. At its core, however, PHC is defined as a set of universally accessible first-level services that promote health, prevent disease, and provide diagnostic, curative, rehabilitative, supportive, and palliative services." This is followed by a list of six broad results that PHC should produce: effectiveness, productivity, accessibility, continuity, quality, and responsiveness. Equity, in the broadest sense as well as in terms of gender, is notably absent. In fact, the authors note that they made an explicit decision to exclude the equity indicator from their analysis due to the "ambiguity of its wording" (8). This depoliticizing of $\mathrm{PHC}$-ignoring health-determining factors outside of the health care system and omitting the right to participate in health care planning and implementation-has contributed to reforms that are focused on systems management, rather than on prevention and equity. Like the 2002 report of the Commission on the Future of Health Care in Canada (9), with its emphasis on individual behaviors and its silence on the structural determinants of health, this approach strips PHC of its radical roots. Moreover, all of these conceptualizations of primary care, including that used in the Declaration of Alma-Ata, ignore the differing PHC needs of men and women.

\section{PRIMARY HEALTH CARE REFORM IN CANADA}

PHC reform is not unique to Canada. It reflects larger, global trends toward changes in health care and health services (9). Nor is PHC a new idea in Canada. Shortly after establishing Medicare, Canada's public medical insurance, John Munro, the Federal Minister of National Health and Welfare of Canada, stated in 1969 (10): "The key is contact, the place is the community, the concept is preventative...group practice, community health 
centers, mobile out-patient clinics, increased casefindings through home visitation, greater availability of local alternate-care institutions, better home care, increased team work with community social agencies."

Even before the Lalonde Report of 1974 (5) and the Declaration of Alma-Ata in 1978, several Canadian provinces pioneered community health centers. Among the first was the province of Saskatchewan, where in 1962 pro-Medicare doctors and citizens formed the Community Health Services (Saskatoon) Association. In the province of Ontario, the Sault Ste. Marie and District Group Health Association opened a clinic in 1963. Shortly after the launching of Medicare, the province of Quebec introduced local community health and service centers. By 1972, the province of Manitoba joined the movement, issuing the White Paper on Health Policy (11), which called for more community health centers and the introduction of district health boards. Later that same year, Munro said the following about community health centers (10): "I think that there are some advantages which are immediately foreseeable. The very fact that the consumer has a real role in the planning, development, and operation of these centers on a community basis represents a substantial step forward (10)."

All of the PHC reform initiatives that took place in the 1960s and 1970s have at least three things in common. First, all are closer to the language and approach of the Declaration of Alma-Ata than the current Canadian PHC reform policies are. Second, none led to major changes in the provision of PHC, which is still primarily delivered by physicians on a fee-for-service basis. Third, none of them acknowledge the importance of gender differences in PHC.

PHC reform has been a high-profile topic in Canada lately, led by the efforts of local and national government leaders and ministers of health. As noted, the First Ministers' Accord on Health Care Renewal identified PHC reform as an area requiring additional investment. In the Accord, the First Ministers stated: "The key to efficient, timely, quality care is PHC reform. First Ministers agree that the core building blocks of an effective PHC system are improved continuity and coordination of care, early detection and action, better information on needs and outcomes, and new and stronger incentives to ensure that new approaches to care are swiftly adopted and here to stay. First Ministers agree that the ultimate goal of PHC reform is to provide all Canadians, wherever they live, with access to an appropriate health care provider, 24 hours a day, 7 days a week."

The First Ministers' statement of their "ultimate goal" as "access to an appropriate health care provider" is telling. Gone is any sense that PHC reform is a tool for improving the health of the most vulnerable, or a means to a more just and equitable society. Access is seen as an end in itself, rather than one factor within the web of health determinants. Equity is not identified as a goal, but efficiency is.

As mentioned previously, the Federal Government of Canada established the PHCTF to provide additional funds to the provinces for health care system changes. The five objectives of the PHCTF were to: (1) increase the proportion of the population with access to PHC organizations that are accountable for the planned provision of comprehensive services to a defined population; (2) increase the emphasis on health promotion, disease and injury prevention, and chronic disease management; (3) increase access to essential services to 24 hours per day and seven days per week; (4) establish multidisciplinary teams, so that the most appropriate care is provided by the most appropriate provider; and (5) facilitate coordination with other health services (such as specialists and hospitals) $(12,13)$.

In framing the purposes and activities of the Accord and PHCTF, the problems of PHC became narrowly defined as lack of access to services and inadequate service integration. Consequently, funding was limited to the health care system. Though the PHCTF formally ended in 2006, the initiatives it spawned continue to shape both the discourse and practice of PHC reform in Canada, including its limited attention to women's health.

The way that PHCTF approached the issues influenced the solutions proposed and the programs that were piloted using the Fund's resources. PHC reform came to be seen as a problem to be solved through better management and the use of appropriate economic incentives and disincentives. Accountability appeared to be about financial accountability to the managers of the system, rather than accountability to communities and users of health services. One can imagine how different the solutions and priorities would have been if the problem had been identified as one of health inequalities, such as inequalities based on sex, socioeconomic status, migration experience, ethnicity, and disability. An improved primary health system may have been part of the solution. The spirit of social justice evident in the Declaration of Alma-Ata has disappeared from the dialogue about PHC reform.

PHC reform is taking place in the context of broader health reform. In Canada, health reform has been characterized by cost containment; reductions in services, particularly through early discharge and the assumption that families, particularly women, will take on increased, unpaid, caregiving roles; and, in some provinces, the introduction of corpo- 
rate management systems and for-profit health services in place of traditionally public ones. These reforms are themselves occurring within the context of larger social and economic forces, notably globalization and international trade agreements. These trade agreements may limit the ability of governments to manage social programs, and may add to the pressure to privatize health care services delivery. Such reforms may be particularly of concern to women in Canada, given women's higher rates of poverty and low income. As Pat Armstrong has noted (14), "Most of those who benefit are men, albeit a small minority of men; most of those who bear the burden and express dissatisfaction with market solutions are women."

\section{WHERE ARE WOMEN IN CANADIAN LITERATURE ABOUT PRIMARY HEALTH CARE REFORM?}

Literature on how the proposed changes in PHC services are expected to impact women is scarce $(15,16)$. Most Canadian research in primary care ignores existing evidence about the impact of gender on health care needs, preferences, and utilization. Three recent synthesis reports dealing with PHC in Canada illustrate this problem $(8,17,18)$.

Even newly published reports designed to inform the PHC reform process often include only sex-aggregated or sex-adjusted data, making even the most cursory male-to-female comparisons impossible. In this process, the rate is adjusted to allow comparisons among different groups by standardizing the sex distribution among the populations. While allowing intergroup comparisons, it masks sex differences. For example, Statistics Canada's Access to Health Care Services in Canada 2001 included only household-level data on barriers to health service access, including PHC, thus making sex disaggregation impossible (19). The 2005 edition includes only sex-aggregated data, even though the source survey, the Canadian Community Health Survey Cycle 3.1, allows for the disaggregation of data by sex (20). This is in sharp contrast to stated commitments to gender-based analysis made by Health Canada, one of the funders of Access to Health Care. The collection and analysis of sex-disaggregated data is an important step, but not sufficient to understand these issues. To fully understand women's health, gender-based analysis that wrestles with issues of women's social status, gender-related power, and access to resources is needed.

Researchers associated with the Centres of Excellence for Women's Health (supported by the
Women's Health Contribution Program of Health Canada) have described the PHC issues of specific groups of women. Their work includes discussions of the needs of drug-dependent women $(21,22)$, immigrant women $(23,24)$, lesbian women $(25)$, minority women (26), Aboriginal women (27-29), and rural women $(30,31)$. These reports approach the issues from the perspective of the women concerned, and draw conclusions about policy and services from their point of view. Interesting work has also been done to develop women-centered models of care, notably the Winnipeg Women's Health Clinic Model of Care (32) and the Vancouver/Richmond Health Authority's Framework for Women-Centred Care (33).

While this literature and the work of other women's health scholars and activists provide valuable information about particular programs and models of care for specific subgroups of women, they do not typically address the different impacts that PHC reforms may have on women as opposed to men; indeed, they were not intended to do so. However, even the existing works and their insights on women's PHC needs do not appear to have been considered by those developing "mainstream" policy initiatives in PHC reform.

\section{WHY FOCUS ON WOMEN'S PRIMARY HEALTH CARE NEEDS?}

Outside of the women's health movement, discussions to date about PHC reform have excluded women's PHC needs and how these might be different from the PHC needs of men. This omission is based on the assumption that gender is not an issue in PHC; that is, that the PHC needs of women and men are the same. Are they?

At the most superficial level, if one examines the First Ministers' five objectives for the PHCTF, these changes will benefit women. After all, don't women need better access to services and better health promotion, prevention, and disease management services? Won't women benefit from access to essential services 24 hours a day, seven days a week? Won't better coordination and interdisciplinary teams of service providers benefit women as well as men?

Of course they do and they will; but beyond these general statements, the differences between women and men, girls and boys, become apparent. We suggest that these differences are manifested in six ways, all of which affect the organization and delivery of PHC. The six ways are described in the following subsections. 


\section{Sex-specific conditions and care needs}

Sex-specific conditions and care needs of women include birth control; prenatal, childbirth, and postnatal care; routine care for menstruation and menopause; female infertility; and periodic cervical cancer screening. These services should be integral to women's PHC. A reformed PHC system should deliver routine reproductive health care in ways that recognize menstruation, pregnancy, childbirth, and menopause as normal physiological processes; that understand women's diversity; and that encourage women's autonomy.

\section{Conditions more prevalent among women}

Conditions more prevalent among women include breast cancer, eating disorders, depression, and self-inflicted injuries $(7,34-36)$. For example, in the case of breast cancer, screening programs should be part of women's routine PHC. In addition, as more women live longer with breast cancer, more of their care becomes the responsibility of the PHC system. In the case of conditions such as eating disorders, depression, and self-inflicted injuries, good PHC for women must include prevention and treatment programs that recognize the gender-specific nature of these conditions, the distinct risk factors, and the need for gender-specific interventions.

\section{Conditions that appear to be sex-neutral}

Conditions that appear sex-neutral include heart disease, a disease whose signs, symptoms, and optimum treatment may differ in women and men (37). Good PHC for women incorporates knowledge of sex and gender differences into all processes of care, including health promotion, disease prevention, and treatment.

\section{The influence of women's gendered roles}

Women's gendered roles in our society influence their health. Examples of this have been documented extensively by women's health researchers and activists, from the effects of caregiving on their own health and financial well-being, to the consequences of women's paid work and working conditions on health, and the impact of women's multiple roles (paid and unpaid) on their health (38-40). Good PHC for women should incorporate this knowledge and be a catalyst for change, helping to reduce the contribution of gender differences to health inequalities.

\section{Gender stereotypes}

Gender stereotypes within the health care system can negatively affect women's health. These stereotypes involve both women's care utilization and caregiving roles. Women are often assumed to use health care services more than men; however, there is good evidence that this is related to sexspecific care and not to male stoicism or to women's predisposition to seek help. For example, in Manitoba in 1994-1995, the per capita cost of providing females with health care services funded by Medicare was approximately $30 \%$ higher than for men. However, after the costs of sex-specific conditions were removed (which for women included normal and abnormal reproduction, and for women and men, diseases of the genitourinary system and of the breast), and considering costs for both physicians' services and acute hospital care, the cost of insured health care services for women was about the same as for men; that is, the female:male ratio went from 1.3 to 1.0 (41). There is also evidence that suggests that stereotypes result in differential treatment in everything from referrals for total joint arthroplasty (hip and knee replacement surgery) (42) and secondary prevention of ischemic heart disease (43) to physicians assuming that women's physical symptoms are psychological in origin (44).

\section{Medicalization of normal aspects of women's lives}

The medicalization of normal life events is most apparent in the care provided to women during pregnancy and childbirth. In Canada, in 2001-2002, about 75\% of all births involved surgical intervention (use of instruments, induction, or epidural/general anesthetic). Interventions can be life-saving, both for mothers and their babies, but they are not risk-free (45). The medicalization approach has been challenged by the women's health movement for over 30 years, with some successnotably the reintroduction of midwifery in some provinces in Canada, and its legitimization as a licensed profession.

\section{CONSIDERING WOMEN'S HEALTH IN PRIMARY HEALTH CARE REFORM}

Despite all of this evidence and the importance of evidence-based medicine and decisionmaking, PHC reform leaders in Canada continue to ignore the overwhelming facts on sex and gender. However, women are not completely omitted in the 
plans for PHC reform. They have been assigned two important roles: vessels (for future human beings) and vectors for the transmission of things to their families, both good (e.g., breast milk, nurturing, health information, nutritious food, caregiving, a physically active lifestyle) and bad (e.g., secondhand smoke, alcohol during pregnancy, junk food, sedentary lifestyle). Every plan for PHC reform includes women as the unnamed and unpaid delivery agents of health promotion, without evaluating how this perpetuates unhealthy gender stereotypes.

Even with the absence of literature on how various models for PHC reform might differentially affect women and men, it is possible to use the lessons learned from other work in women's health and apply them to these proposals. A discussion of these follows, using the five objectives of the PHCTF as a framework.

\section{Increase the proportion of the population having access to PHC organizations}

This objective emphasized the development of PHC organizations that provide a defined set of comprehensive services to a defined population. This approach could include many organization types, from physician group practices, to managed primary health services based on rostering and capitation, to community health centers. It raises a number of concerns, such as who defines "the set of comprehensive services." In physician-managed alternatives, such as the province of Ontario's Family Health Networks, this is determined through negotiation between physicians and their representatives and government and/or regional health authorities. The sex-specific and gender-specific primary health needs of women are unlikely to be considered in these negotiations. In community health centers in Canada, community-based boards set their own service priorities, based on their perceptions of community needs (which may or may not be sensitive to women's health issues) and in negotiations with their funders (either the provincial government directly or a regional health authority). While some of the most innovative, gender-sensitive PHC programs have been developed by community health centers, others have focused on "family health," in which women are valued for their work as vectors for transmitting health information, but their distinct health needs receive little attention.

What will be included in a "defined set of services"? These are crucial issues for women's health, particularly the overmedicalization of women's normal reproductive physiology described previously. Will existing knowledge about sex and gen- der differences be used to design, implement, and evaluate services? Will the service needs of all women be assumed to be the same, or will knowledge about differences among women (for reasons such as disability, migration, Aboriginal ancestry, minority status, and sexual orientation) be considered? Will existing knowledge about the ways that gender interacts with the other determinants of health, such as income, education, and social and physical environments, be included?

Who will constitute the "defined population"? Unfortunately, women still encounter discriminatory treatment from physicians and other health care providers who are not sensitive to their needs. Examples of this include lack of detailed knowledge of sex-specific conditions (for example, endometriosis) and biased attitudes (for example, that women complain and seek help more often). Therefore, systems such as rostering, which limit women's abilities to seek a second opinion without the consent of the designated family physician, are not good for women's health. (In Ontario, patients enrolled in Family Health Networks must be referred by their participating family doctor to a second family physician, should they wish a second opinion. This system may limit patient autonomy and privacy [see Family Health Network patient brochure, available from http: / / www.ontariofamily healthnetwork.gov.on.ca/english/index.html]).

How will the views of women who use the health care system be included in designing, implementing, and evaluating these organizations? Their views as health care system users and as informal, unpaid care providers are rarely reflected in PHC research and policy development.

How will new organizational models recognize the increasing number of female care providers in the health services system? The number of female family physicians in Canada continues to increase. In 2002, they were the majority of family physicians under the age of 35 (46). On average, female family physicians practice fewer hours than their male counterparts do (47). Female family physicians are also more likely to include obstetrics and mental health services in their practices, and they are less likely to see patients in the hospital, to perform basic surgical procedures, and to provide anesthesia (46). Since most PHC reform models rest upon family or general practitioners, and women account for an increasing proportion of family physicians, the organization of primary care needs to reflect these differences. In addition, PHC reform should consider differences in the ways that female and male family practitioners organize their practices, balance family responsibilities, engage in relationships with patients, and respond to government health policies (48-50). 
Increase emphasis on health promotion, prevention, and management

The explicit inclusion of health promotion and prevention in PHC is welcome. One of the major criticisms of fee-for-service payment systems in Canada has been that they do not reward family physicians who take the time to work with their patients on promotion and prevention. How health promotion and prevention are understood will be critical to their success and to improving women's health. For example, will health promotion focus on the behavioral determinants of health, such as diet, smoking, and exercise, or will adequate resources be attached to challenging and changing the structural determinants of health, such as income, working conditions, and education? Given the current definitions of PHC reform, this does not appear to be the case.

Will gender, its role as a determinant of health, and its interactions with other determinants be considered in the design, implementation, and evaluation of these programs? Given the absence of gender analysis from current plans for PHC reform, it does not appear likely.

Will health promotion and prevention programs promote gender stereotypes by treating women as vectors and vessels? To the extent that these campaigns individualize problems and blame women for their own ill health and that of their families, they compound women's sense of responsibility for health problems that are, in fact, largely beyond their control (51). There is little evidence to suggest that these practices are changing.

\section{Expand 24/7 access to essential services}

Expanded access to services is a good idea. However, "access" for women means more than an open door, or someone answering the telephone, 24 hours a day and seven days a week ("24/7"). Many questions need to be answered. What services will be provided over the phone? What does access to PHC 24/7 really mean? The expectation is that additional services will be provided outside of normal office hours. Working women will benefit from the expansion beyond normal office hours. They will be able to seek PHC for themselves in the evening, for example. However, what effect will establishing such hours have on the health of care providers, the majority of whom are women? In particular, 24/7 access in Canada is often understood to mean access to "tele-health" services provided by nurses by telephone. How do we therefore balance the conflicting desires and needs of women from both of these perspectives? Will child care services be available to women who need to seek care for themselves? What measures are needed to make services accessible to women with physical disabilities? How can services be culturally and linguistically accessible to women from minority communities? Will service providers recognize that women's work and family commitments limit their ability to seek care?

\section{Establish interdisciplinary PHC teams of providers}

While a comprehensive approach to health, including health promotion and disease prevention, is important for women's health and wellbeing, and the greater use of multidisciplinary and interdisciplinary teams has the potential to increase the quality of care available, there remain concerns for women. How will the appropriate mix of team members be established? How will adequate training for sex- and gender-sensitive health care be ensured? How do we ensure that the patient/client is involved as an active member of this "team" and that continuity of care is maintained?

\section{Facilitate coordination and integration with other health services}

Increased facilitation and coordination are also welcome. However, this is frequently reduced to a discussion of an electronic medical record to address the desire for a seamless flow of health information. This raises two concerns. First, it fails to recognize a woman's desires to protect the private nature of her discussions with her PHC provider or specialist. For example, a patient may not wish to discuss an abortion, or the decision to place a child for adoption, if she knows this information will be available to others. Similarly, domestic violence may not be disclosed if the information will be included in a chart that is available to other community agencies and institutions. These issues are especially acute for women in rural and remote communities. Secondly, an electronic medical record is the solution to a very narrow definition of "coordination and integration." The original promise of PHC reform as an opportunity to improve continuity and flexibility of care appears to have been lost.

\section{GENDER-SENSITIVE PRIMARY HEALTH CARE REFORM}

Despite a subsequent expansion of the definition of primary care to a definition of PHC more 
consistent with the spirit of the Declaration of Alma-Ata being described in this paper, the radical spirit of Alma-Ata has been essentially absent from current PHC reform in Canada. Even the revised definition makes a distinction between primary health care and primary care, with the latter focusing on first point of access to the health care system, rather than focusing on the broad determinants of health. If PHC reform is limited to changing management, governance, and payment processes, its potential to contribute to reducing health inequalities will be lost. To improve and promote women's health, PHC reform should incorporate existing knowledge about how sex and gender influence women's health, and about when and how this influence is different for women and men. PHC reform should also identify areas that need additional research.

A reformed PHC system that is not gendersensitive has the potential to reinforce stereotypes by treating women as vessels and vectors. This is damaging to women's health because it limits the ways in which the health care system defines and addresses women's health needs as well as perpetuates a limited understanding of women's contributions to health and health care. By incorporating gender-based analysis into health care design and delivery and inviting women to contribute to reforms, PHC will be better equipped to meet their needs. If we adopt the experience of community health centers in Canada and encourage women in local communities to become involved in the design and governance of PHC reform, their health may benefit from a system designed with their needs in mind. However, without employing mechanisms such as gender-based analysis and engaging women in the reform process, PHC reform in Canada will fail to achieve its full potential.

Acknowledgements. We would like to thank the members of Women and Health Care Reform, a national working group studying health care re- form and its implications for women in Canada, for their comments on an earlier draft. Members include: Pat Armstrong, Madeline Boscoe, Barbara Clow, Karen Grant, Margaret Haworth-Brockman, Beth Jackson, Morgan Seeley, and Kay Willson. The feedback of the participants to the February 2004 National Workshop on Women and Primary Health Care Reform was also appreciated. The views expressed herein represent those of the authors and are not necessarily those of Women and Health Care Reform or of its funder, the Women's Health Contribution Program, Health Canada.

\section{SINOPSIS}

\section{Más allá de vectores y portadoras: reflexiones sobre la mujer y la reforma de la atención primaria de salud en Canadá}

La reforma de la atención primaria de salud (APS) tradicional en Canadá está enfocada en la modificación del proceso de pago a los médicos y en el perfeccionamiento de la eficiencia organizacional. Aunque algunos de los cambios propuestos benefician a las mujeres, puede que otros no. Es necesario hacer un análisis explícito de género de los diversos modelos de reforma de la APS. Como las mujeres y los hombres tienen desiguales necesidades de salud y utilizan los servicios de salud de manera diferente, las reformas que tomen en cuenta estas diferencias serán más eficaces. Además, un enfoque más amplio al implementar la APS, que esté más cerca del espiritu de la Declaración de Alma-Ata e incorpore un análisis basado en el género, aumentará la eficacia de la APS con relación a las mujeres en Canadá.

Palabras clave: atención primaria de salud, economía en atención de salud y organizaciones, accesibilidad a los servicios de salud, prestación de atención de salud, Canadá.

\section{REFERENCES}

1. Health Canada. 2003 First Ministers' Accord on Health Care Renewal [Internet site]. Ottawa: Health Canada. Available from: http://www.hc-sc.gc.ca/ hcs-sss/delivery-prestation/fptcollab/ 2003accord/index_e.html\#notes. Accessed 18 October 2006.
2. World Health Organization. Declaration of Alma-Ata international conference on primary health care, Alma-Ata, USSR, 6-12 September 1978 [Internet site]. Geneva: WHO. Available from: http://www.who.int/hpr/NPH/docs/ declaration_almaata.pdf. Accessed 10 October 2006.

3. Ehrenreich B, English D. Complaints and disorders: the sexual politics of sickness. 1st ed. Old Westbury: Feminist Press; 1976. 
4. Health Canada. Women's health strategy [Internet site]. Ottawa: Health Canada. Available from: http://www. hc-sc.gc.ca/ahc-asc/pubs/strategwomen-femmes/strateg_e.html. Accessed 18 October 2006.

5. Lalonde M. A new perspective on the health of Canadians. Ottawa: Minister of Supply and Services Canada; 1974.

6. Health Canada. Health Canada's genderbased analysis policy. Ottawa: Minister of Public Works and Government Services Canada; 2000.

7. Women's Health Bureau, Health Canada. Exploring concepts of gender and health. Ottawa: Health Canada; 2003.

8. Lamarche P, Beaulieu M-D, Pineault R, Contandriopoulos A-P, Denis J-L, Haggerty J. Choices for change: the path for restructuring primary healthcare services in Canada. Ottawa: Canadian Health Services Research Foundation; 2003.

9. Armstrong P, Boscoe M, Clow B, Grant K, Pederson A, Willson K, et al. Reading Romanow: the implications of the final report of the commission on the future of health care in Canada for women. Toronto: National Coordinating Group on Health Care Reform and Women; 2003.

10. Government of Manitoba. White paper on health policy, Appendix Vol. 1. Winnipeg: Province of Manitoba; 1972.

11. Miller SA. White paper on health policy. Winnipeg: Province of Manitoba; 1972.

12. Health Canada. Objectives of the primary health care transition fund [Internet site]. Ottawa: Health Canada. Available from: http://www.hc-sc.gc.ca/ hcs-sss / prim/phctf-fassp/object_e. html. Accessed 24 October 2006.

13. Devreaux PJ, Choi PJ, Lacchetti C, Weaver $B$, Schünemann $\mathrm{H}$, Haines $\mathrm{T}$, et al. A systematic review and metaanalysis of studies comparing mortality rates of private for-profit and private not-for-profit hospitals. CMAJ. 2002;166 (11):1399-406.

14. Armstrong P. The context for health care reform in Canada. In: Armstrong $\mathrm{P}$, Amaratunga C, Bernier J, Grant K, Pederson A, Willson K, eds. Exposing privatization: women and health care reform in Canada. Aurora: Garamond Press; 2001. Pp. 11-48.

16. Schellenberg C. Primary [health] care and women: an annotated bibliography. Toronto: National Coordinating Group on Women and Health Care; 2001.

17. Armstrong P, Armstrong H. Women, privatization and health care reform: the Ontario case. In: Armstrong P, Amaratunga C, Bernier J, Grant K, Pederson A, Willson K, eds. Exposing privatization: women and health care reform in Canada. Aurora: Garamond Press; 2001. Pp. 163-215.

18. Canadian Institute for Health Information. Health care in Canada 2003. Ottawa: Canadian Institute for Health Information; 2003.
19. Health Council of Canada. Primary health care: a background paper to accompany health care renewal in Canada: accelerating change. Ottawa: Health Council of Canada; 2005.

20. San Martin C, Houle C, Berthelot J-M, White K. Access to health services in Canada, 2001. Ottawa: Minister of Industry; 2002.

21. Statistics Canada. Access to health care services in Canada January to December 2005. Ottawa: Minister of Industry; 2006.

22. Poole N, Isaac B. Apprehensions: barriers to treatment for substance-using mothers. Vancouver: Centre of Excellence for Women's Health; 2002.

23. Tait C. A study of the service needs of pregnant addicted women in Manitoba, Winnipeg: Prairie Women's Health Centre of Excellence; 2000.

24. MacKinnon M, Howard L. Affirming immigrant women's health: building inclusive health policy. Halifax: Maritime Centre of Excellence for Women's Health; 2000.

25. Weerasinghe S. Equitable access to healthcare, health promotion and disease prevention for recent immigrant women living in Nova Scotia, Canada: report on phase 1. Halifax: Maritime Centre of Excellence for Women's Health; 2000.

26. Anderson L, Healy T, Herringer B, Isaac B, Perry T. Out in the cold: the context of lesbian health in northern British Columbia. Vancouver: Centre of Excellence for Women's Health; 2001.

27. Sharif N, Dar A, Amaratunga C. Ethnicity, income and access to health care in the Atlantic region: a synthesis of the literature. Halifax: Maritime Centre of Excellence for Women's Health; 2000.

28. Browne A, Fiske J, Thomas G. First Nations women's encounters with mainstream health care services and systems. Vancouver: Centre of Excellence for Women's Health; 2000.

29. Benoit C, Carroll D, Lawr L. Marginalized voices from the Downtown Eastside: aboriginal women speak about their health experiences. Toronto: National Network on Environments and Women's Health; 2001.

30. Deiter C, Otway L. Sharing our stories on promoting health and community healing: an Aboriginal women's health project. Winnipeg: Prairie Women's Health Centre of Excellence; 2001.

31. Roberts J, Falk M. Women and health: experiences in a rural regional health authority. Winnipeg: Prairie Women's Health Centre of Excellence; 2002.

32. Donner L. A rural women's health program: the experience of the South Westman Regional Health Authority. Winnipeg: Prairie Women's Health Centre of Excellence; 2001.

33. Women's Health Clinic of Manitoba. WHC model of care [Internet site]. Winnipeg: Women's Health Clinic of Manitoba. Available from: http://www.
womenshealthclinic.org/WHC model html. Accessed 24 October 2006.

34. Vancouver/Richmond Health Board. A framework for women-centred health. Vancouver: Vancouver/Richmond Health Board; 2001.

35. Donner L. Including gender in health planning: a guide for regional health authorities. Winnipeg: Prairie Women's Health Centre of Excellence; 2003.

36. Greaves L, Hankivsky O, Amaratunga C, Ballem P, Chow D, De Konick M, et al. CIHR 2000: sex, gender and women's health. Vancouver: British Columbia Centre of Excellence for Women's Health; 1999.

37. Fransoo R, Martens P, Burland E, Prior $\mathrm{H}$, Burchill C, Chateau D, et al. Sex differences in health status, health care use and quality of care: a population-based analysis for Manitoba's regional health authorities. Winnipeg: Manitoba Centre for Health Policy; 2005.

38. Grace S, Cheung A, Stewart D. Cardiovascular disease [Internet site]. In: DesMeules M, Stewart D, eds. Women's health surveillance report: a multidimensional look at the health of Canadian women. Available from: http:// www.phac-aspc.gc.ca/publicat/whsrrssf/pdf/WHSR_Chap_14_e.pdf. Accessed 24 October 2006.

39. Maclean H, Glynn K, Ansara D. Multiple roles and women's mental health in Canada [Internet site]. In: DesMeules $\mathrm{M}$, Stewart D, eds. Women's health surveillance report: a multi-dimensional look at the health of Canadian women. Available from: http://secure.cihi.ca/ cihiweb/products/WHSR_Chap_2_e. pdf. Accessed 25 October 2006.

40. Colman R. A Profile of women's health indicators in Canada. Ottawa: Health Canada, Women's Health Bureau; 2003.

41. Donner L. Background report: producing a profile of Manitoba women's health. Winnipeg: Prairie Women's Health Centre of Excellence; 2004.

42. Mustard C, Kaufert P, Kozyrskyj A. Mayer T. Sex differences in the use of health care services. N Engl J Med. 1998; 338(23):1694-5.

43. Jackson, BE, Pederson A, Boscoe M Gender-based analysis and wait times: new questions, new knowledge [Internet site]. Available from: http://www. hc-sc.gc.ca/hcs-sss/pubs/care-soins/ 2006-wait-attente / gender-sex / index_e.html. Accessed 24 October 2006.

44. Hippisley-Cox J, Pringle M, Crown N, Meal A, Wynn A. Sex inequalities in ischaemic heart disease in general practice: cross sectional survey. BMJ. 2001; 322:832-6.

45. McKinlay JB. Some contributions from the social system to gender inequalities in heart disease. J Health Soc Behav. 1996;37(1):1-26.

46. Canadian Institute for Health Information. Giving birth in Canada: a regional profile. Ottawa: Canadian Institute for Health Information; 2004. 
47. Tepper J. The evolving role of Canada's family physicians 1992-2001. Ottawa: Canadian Institute for Health Information; 2004.

48. College of Family Physicians of Canada. Janus snapshots-work hours [Internet site]. Ottawa: College of Family Physicians of Canada. Available from: http:// www.nationalphysiciansurvey.ca/nps/ reports/PDF-e/Janus_Snapshots_Work Hours.pdf. Accessed 25 October 2006.
49. Woodward CA, Hutchison BG, Abelson J, Norman G. Do female primary care physicians practise preventive care differently from their male colleagues? Can Fam Physician. 1996;42: 2370-9

50. Tudiver S, Hall M. Canada-U.S.A. Women's Health Forum on Health Care Delivery: women and health care delivery in Canada [Internet site]. Available from: http://www.hc-sc.gc.ca/hl-vs/ pubs/women-femmes/can-usa/can- back-promo_9_e.html. Accessed 24 October 2006

51. Daykin N, Naidoo J. Feminist critiques of health promotion. In: Bunton R, Nettleton S, Burrows R, eds. The sociology of health promotion: critical analyses of consumption, lifestyle and risk. London and New York: Routledge; 1995. Pp. 59-69.

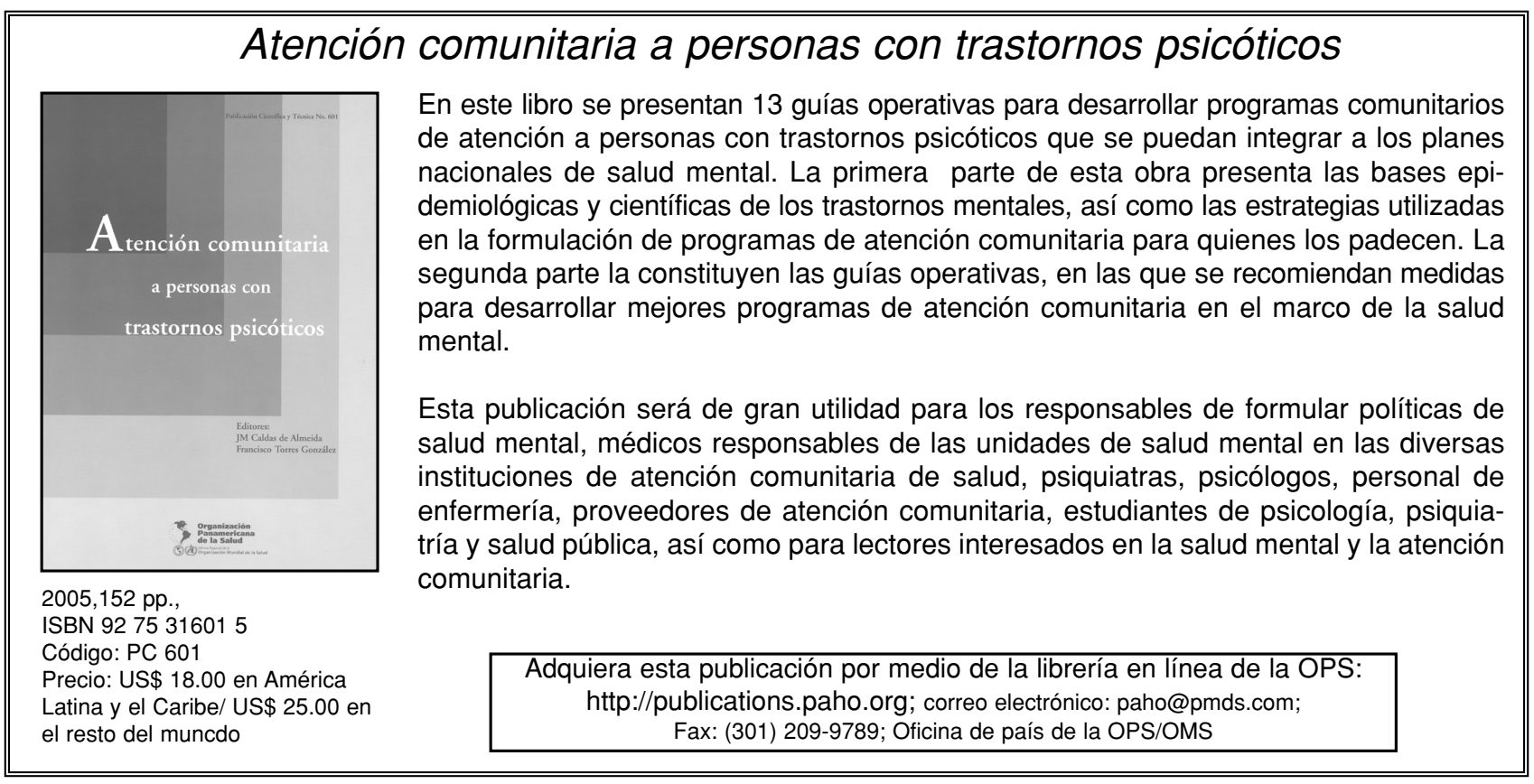

